\title{
Lif boyunun ve içeriğinin geopolimer betonların asit direncine etkisi
}

\author{
The effect of fiber length and content on acid resistance of geopolymer concrete
}

Fatih KANTARCI*1,a

İnönü Üniversitesi, Mühendislik Fakültesi, İnşaat Mühendisliği Bölümü, 44280, Malatya

\begin{tabular}{|c|c|c|}
\hline - Geliş tarihi / Received: 21.01.2021 & • Düzeltilerek geliş tarihi / Received in revised form: 19.02 .2021 & - Kabul tarihi / Accepted: 28.02 .2021 \\
\hline
\end{tabular}

\begin{abstract}
$\ddot{O} z$
Çimento üretimi beraberinde birçok ekonomik ve çevresel sorunu getirerek yıldan yıla artışını sürdürmektedir. Çimentoya alternatif bağlayıcı arayışları 21. yüzyılın en popüler araştırma konuları arasında yer almaktadır. Yapılan çalışmalarda alkali aktive edilmiş bağlayıcılar olarak da adlandırılan "geopolimer" bağlayıcılar öne çıkmaktadır. Geopolimerler yüksek silis ve alümin içeriğine sahip doğal ve atık puzolanların yüksek alkali ortamlarda aktive edilmesiyle elde edilen yeni nesil üç boyutlu bağlayıcılardır. Geopolimer bağlayıcılar normal Portland çimentolu bağlayıcılar ile kıyaslandığında dayanım, dayanıklılık ve ekonomik açıdan oldukça önemli avantajlara sahiptirler. Ancak geopolimer betonların yaygın kullanımının önündeki en önemli engel, üretiminde ihtiyaç duyulan ısıl kür işlemidir. Lif boyunun ve içeriğinin lifli geopolimer betonların asit direncine etkisi üzerine ise literatürde çalışma bulunmamaktadır. Bu çalışmada, lif boyunun ve lif içeriğinin 1sıl kür işlemi uygulanmadan üretilmiş geopolimer betonların asit direncine etkisi ortaya çıkarılmıştır. Bu amaçla 6 ve $12 \mathrm{~mm}$ boylarında polipropilen (PP) lif, hacimce \%0.5, \%1.0 ve \%1.5 oranlarında ilave edilmiştir. Alüminosilikat kaynağı olarak yüksek firın cürufu (YFC) kullanılmıştır. Laboratuar koşullarında 28 gün kür edilen geopolimer beton numuneleri daha sonra 14 ve 28 gün boyunca $\% 5 \mathrm{HCl}$ çözeltisine maruz bırakılmıştır. Asit etkisi sonrasında, geopolimer betonların basınç dayanımı, ağırlık, ultra ses hızı (UPV), dış görünüş gibi fiziksel ve mekanik özelliklerindeki değişimler araştırılmıştır. Ayrıca SEM analizleri ile mikro yapıları incelenmeleri gerçekleştirilmiştir. Yapılan deneysel çalışmalar neticesinde, PP lif katkısının köprüleme etkisiyle çatlak oluşumunu engellediği için geopolimer betonların asit direncini önemli ölçüde iyileştirdiği tespit edilmiştir.
\end{abstract}

Anahtar kelimeler: Asit direnci, Geopolimer, Lif boyu, Lif içeriği

\begin{abstract}
Cement production continues to increase year by year, bringing many economic and environmental problems. The search for alternative binders to cement is among the most popular research topics of the 21st century. In the studies conducted, "geopolymer" binders, also called alkali activated binders, stand out. Geopolymers are the new generation threedimensional binders obtained by activating natural and waste pozzolans with high silica and alumina content in high alkaline environments. Geopolymer binders have quite important advantages in terms of strength, durability and economy when compared to normal Portland cement binders. However, the most important obstacle to the widespread use of geopolymer concretes is the thermal curing process required in its production. There is no study in the literature on the effect of fiber length and content on acid resistance of fiber reinforced geopolymer concretes. In this study, the effect of fiber length and fiber content on acid resistance of geopolymer concretes produced without heat curing was revealed. For this purpose, 6 and $12 \mathrm{~mm}$ length polypropylene (PP) fiber was added at the rate of $0.5 \%, 1.0 \%$ and $1.5 \%$ by volume. Blast furnace slag (BFS) was used as an aluminosilicate source. Geopolymer concrete samples cured for 28 days in laboratory conditions were then exposed to 5\% $\mathrm{HCl}$ solution for 14 and 28 days. The changes in the physical and mechanical properties of geopolymer concrete such as compressive strength, weight, ultrasonic pulse velocity (UPV), visual appearance after acid effect were investigated. In addition, microstructures were examined with SEM analyzes. As a result of the experimental studies, it has been determined that the PP fiber additive significantly improves the acid resistance of geopolymer concretes as it prevents the formation of cracks with the bridging effect.
\end{abstract}

Keywords: Acid resistance, Geopolymer, Fiber length, Fiber content

*a Fatih KANTARCI; fatih.kantarci@inonu.edu.tr, Tel: (0422) 37748 81, orcid.org/0000-0001-6863-995X 


\section{Giriş}

Portland çimentosu, 2019 yılı itibarı ile yıllık 4.2 milyar ton üretim kapasitesini aşan vazgeçilmez bir yap1 malzemesidir (Ganesh ve Muthukannan, 2021). Artan talep ile paralel olarak çimento üretiminin 2050 yılında 6.1 milyar ton olacağ tahmin edilmektedir (Ranjbar ve Zhang, 2020; Scrivener vd., 2018). Çimento üretimindeki bu artış beraberinde birçok ekonomik ve çevresel sorunu getirmektedir. Kalkerin ve fosil yakıtların yakılmasına bağlı olarak, 1 ton Portland çimentosu imalatı için yaklaşık olarak 1 ton $\mathrm{CO}_{2}$ salınımı meydana gelmektedir (Davidovits, 1993; Davidovits, 1994; Malhotra, 1999; Kajaste ve Hurme, 2016; Assi vd., 2018; Moradikhou vd., 2020). Dünyada toplam $\mathrm{CO}_{2}$ salınımının \%7'sinin çimento endüstrisinden kaynaklandığ bilinmektedir (Meyer, 2009; Shi vd. 2012). Bu oranının önümüzdeki birkaç yıl içerisinde \%17'ye ulaşacağı tahmin edilmektedir (El-Gamal ve Selim, 2017; Damilola, 2013). $\mathrm{CO}_{2}$ salınımının neden olduğu sera gazı etkisi küresel sıcaklığı arttırmakta ve iklim değişikliklerine neden olmaktadır. İklim değişikliği yeryüzündeki organizmaların varlığını tehdit eden önemli sorunlardan biridir. Ayrica çimento üretimi yüksek sicaklıklarda gerçekleştirildiğinden $4.8 \mathrm{GJ} / \mathrm{t}$ değerinde enerji sarfiyatı gerektirmektedir (Ranjbar ve Zhang, 2020; Worrell vd., 2001). Enerji fiyatlarındaki artışlar ise çimento üretim maliyetini de arttırmaktadır.

Yukarıda bahsedilen ekonomik ve çevresel nedenlerden ötürü Portland çimentosuna alternatif bağlayıcı arayışları 21. yüzyılda ivme kazanmıştır. Son yıllarda yapılan çalışmalar, alkali aktive edilmiş ya da geopolimer bağlayıcılar olarak adlandırılan yeni nesil bir bağlayıcı türü üzerine yoğunlaşmıştır. Geopolimer terimi ilk defa 1978 yılında Fransız araştırmacı Davidovits tarafindan alüminosilikat esaslı inorganik polimerlerin tanımı için kullanılmıştır. Geopolimerler uçucu kül, yüksek firın cürufu, tüf, pomza, perlit gibi doğal ve atık puzolanların yüksek alkali çözeltisi ile sentezlenmesi sonucu elde edilen yeni nesil bir bağlayıcı türüdür. Geopolimer bağlayıcılar Portland çimentosu ile kıyaslandığında ekonomik, çevresel ve durabilite özellikleri açısından birçok avantaja sahiptir. Geopolimerler, reaktivitesi, maliyeti ve miktarı bakımından farklı birçok alüminosilikat hammaddeden üretilebilir (Davidovits, 2008). Çimentoya alternatif olarak önerilen geopolimerler, çimento üretiminden kaynaklanan $\mathrm{CO}_{2}$ emisyonların $\% 80$ oranında azaltabilir (Duxson vd., 2007; Davidovits, 2011; Ganesh ve Muthukannan, 2021). Geopolimer üretiminin Portland çimento üretimine kıyasla $\% 60$ oranında enerji tasarrufu sağladığı (Comrie ve Davidovits, 1988; Davidovits vd., 1990) ve $\% 75$ oranında daha ekonomik olduğu çeşitli çalışmalarda ifade edilmiştir (Singh, 2018; Ganesh ve Muthukannan, 2021).

Asit etkisi betonun servis ömrünü önemli ölçüde azaltan çevresel etkilerden bir tanesidir. Asidik ortam doğal olarak meydana gelebileceği gibi tarım, endüstriyel ve kentsel faaliyetler sonucunda da oluşabilir (Kwasny vd., 2018). Asit saldırısı sonucunda oluşan tahribatın boyutu, etki eden asitin tipi, konsantrasyonu, etkime süresi ve beton özelliklerine bağlı olarak değişir (Kwasny vd., 2018; Zivica ve Bajza, 2002; Beddoe ve Dorner, 2005). Asit etkisine maruz kalan geopolimer betonlarda bozulma alüminosilikat yapının kırılması sonucu meydana gelir (Bakharev, 2005). Asit etkisi sonucunda basınç dayanımında görülen düşüş esas olarak bu yapının kırılması sonucunda meydana gelen çatlak oluşumu ile alakalıdır (Djobo vd., 2016). Geopolimer betonların üç boyutlu alüminosilikat yapılarından dolayı asit etkilerine karşı üstün direnç gösterdiği çeşitli çalışmalarda vurgulanmıştır (Palomo vd., 1999; Sata vd. 2012; Bakharev vd., 2003; Ganesh ve Muthukannan, 2021; Moradikhou vd., 2020).

Lifler düşük maliyetleri ve üstün özellikleri nedeniyle son y1llarda beton üretiminde yoğun olarak tercih edilmektedirler. Betonun zayıf olan çekme ve çatlak oluşumu direncinin lif katkısı ile geliştirilmesi amaçlanmaktadır. Cam elyaf, polipropilen (PP), çelik, bazalt, karbon vb. lifler toplam beton hacminin yüzdesi olarak karışıma ilave edilmektedir (Dawood ve Ramli, 2011; Sabu ve Karthi, 2018; Reed vd., 2014; Aswani ve Karthi, 2017). Lifli geopolimer betonlar ise görece olarak yeni bir araştırma konusudur. Lif tipi, çapı, boyu, oranı ve karıştırma yöntemi geopolimer betonun özelliklerini doğrudan etkiler. Lif boyunun ve oranının geopolimer betonların asit direncine etkisi üzerine literatürde çalışmaya rastlanmamıştır. $\mathrm{Bu}$ çalışmanın yeniliğ̣i, lif boyunun ve lif içeriğinin 1 sıl kür işlemi uygulanmadan üretilmiş geopolimer betonların asit direncine etkisini ortaya çıkarmasıdır. Bu amaçla 6 ve $12 \mathrm{~mm}$ boylarında PP lif, hacimce $\% 0.5, \% 1.0$ ve 1.5 oranlarında ilave edilmiştir. Laboratuar koşullarında 28 gün kür edilen geopolimer beton numuneleri daha sonra 14 ve 28 gün boyunca $\% 5$ $\mathrm{HCl}$ çözeltisine maruz bırakılmıştır. Asit etkisi sonrasında, geopolimer betonların basınç dayanımı, ağırlık, ultra ses hızı (UPV), dış görünüş gibi fiziksel ve mekanik özelliklerindeki 
değişimler araştırılmıştır. Ayrıca SEM analizleri ile mikro yapıları incelenmeleri gerçekleştirilmiştir.

\section{Materyal ve metot}

\subsection{Materyal}

\subsubsection{Yüksek firın cürufu (YFC)}

Bağlayıcı malzeme alüminosilikat kaynağı olarak kullanılan YFC Karçimsa Çimento Sanayi ve Ticaret A.Ş'den tedarik edilmiştir. YFC'nin kimyasal bileşimleri Tablo 1'de verilmiştir.
YFC'nin özgül ağırlığı 2.86, özgül yüzeyi ise 3940 $\mathrm{cm}^{2} / \mathrm{g}$ 'dır.

\subsubsection{Sodyum hidroksit ( $\mathrm{NaOH})$}

Geopolimer bağlayıcı üretiminde sıklıkla kullanılan alkali aktivatör, kolay bulunabilirliği, düşük maliyeti ve düşük viskozitesi nedeniyle $\mathrm{NaOH}$ çözeltisidir. $\mathrm{Bu}$ sebeple bu çalışmada da $\mathrm{NaOH}$ tercih edilmiștir. $\mathrm{NaOH}$ aktivatörünün bazı kimyasal ve fiziksel özellikleri Tablo 2'de verilmiştir.

Tablo 1. YFC'nin kimyasal bileşimleri

\begin{tabular}{cccccccccc}
\hline Bileşen, (\%) & $\mathrm{SiO}_{2}$ & $\mathrm{Al}_{2} \mathrm{O}_{3}$ & $\mathrm{Fe}_{2} \mathrm{O}_{3}$ & $\mathrm{CaO}$ & $\mathrm{SO}_{3}$ & $\mathrm{Na}_{2} \mathrm{O}$ & $\mathrm{MgO}$ & $\mathrm{TiO}_{2}$ & $\mathrm{Mn}_{2} \mathrm{O}_{3}$ \\
\hline YFC & 32.47 & 9.94 & 1.25 & 32.45 & 0.82 & 0.31 & 9.31 & 1.16 & 3.51 \\
\hline
\end{tabular}

Tablo 2. $\mathrm{NaOH}$ alkali aktivatörünün bazı kimyasal ve fiziksel özellikleri

\begin{tabular}{cc}
\hline & Sodyum Hidroksit \\
\hline Kimyasal formülü & $\mathrm{NaOH}$ \\
Moleküler kütle, $(\mathrm{g} / \mathrm{mol})$ & 39.997 \\
Asitlik & Çok düşük $(\mathrm{pH}: 13-14)$ \\
Çözünürlük, $(\mathrm{g} / \mathrm{l})$ & $1110\left(+20^{\circ} \mathrm{C}{ }^{\prime} \mathrm{de}\right)$ \\
Renk & Beyaz \\
Yoğunluk, $\left(\mathrm{g} / \mathrm{cm}^{3}\right)$ & 2.13 \\
Kaynama noktas $1,\left({ }^{\circ} \mathrm{C}\right)$ & 1390 \\
Erime noktasi,$\left({ }^{\circ} \mathrm{C}\right)$ & 318 \\
Donma noktas,$\left({ }^{\circ} \mathrm{C}\right)$ & 14 \\
\hline
\end{tabular}

\subsubsection{Su}

Deneysel çalışmada kullanılan alkali aktivatör çözeltisi TS EN 1008 standardına uygun olan musluk suyu ile hazırlanmıştır. Karışıma çözelti haricinde ilave su katılmamıştır.

\subsubsection{Agrega}

Yapılan deneme dökümleri neticesinde, agrega tane çap1 arttıkça basınç dayanımının düştüğü gözlemlendiğinden agrega maksimum tane çap 18 $\mathrm{mm}$ olarak seçilmiştir. Agregalar 0-2 mm, 2-4 mm ve 4-8 $\mathrm{mm}$ tane gruplarına ayrılmıştır (Şekil 1). Agregaların bazı fiziksel özellikleri TS EN 1097-6 standardına göre tespit edilmiş ve Tablo 3'de verilmiştir. Ayrıca agregalar üzerinde TS EN 17441 standardına uygun olarak organik madde içeriği deneyi yapılmış ve kullanımının uygun olduğu tespit edilmiştir.

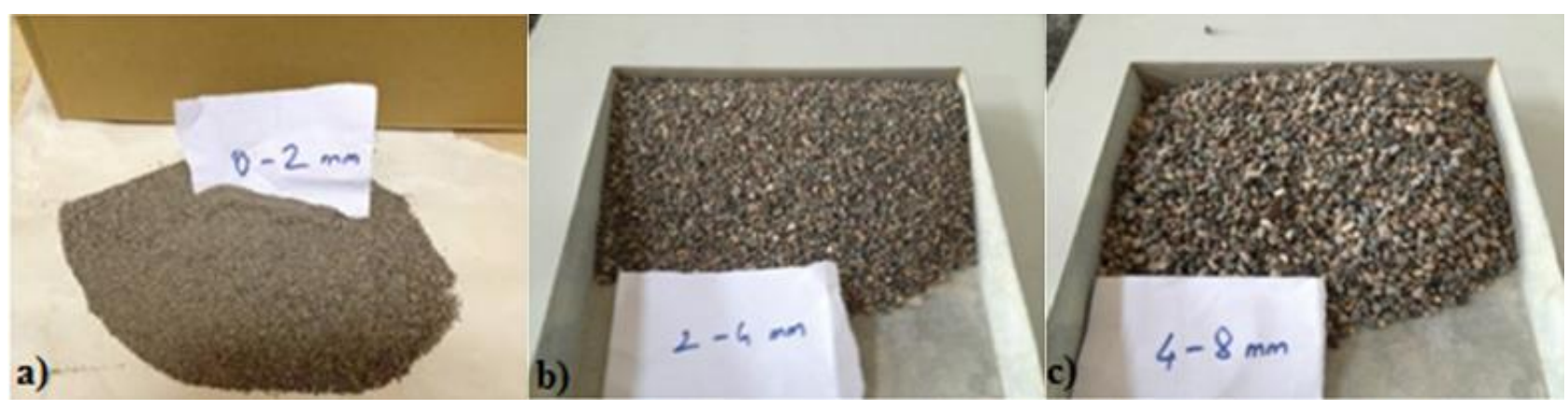

Şekil 1. Dere agregası; a) 0-2 mm, b) 2-4 mm, c) 4-8 mm 
Tablo 3. Agregaların fiziksel özellikleri

\begin{tabular}{lccc}
\hline & \multicolumn{3}{c}{ Dere agregas } \\
\cline { 2 - 4 } & $0-2 \mathrm{~mm}$ & $2-4 \mathrm{~mm}$ & $4-8 \mathrm{~mm}$ \\
\hline Kuru özgül ağırlık & 2.35 & 2.46 & 2.51 \\
Doygun kuru yüzey özgül ağırlık & 2.42 & 2.52 & 2.57 \\
Su emme oranı, (\%) & 2.65 & 2.05 & 1.95 \\
\hline
\end{tabular}

\subsubsection{PP lif}

Deneysel çalışmada $6 \mathrm{~mm}$ ve $12 \mathrm{~mm}$ boylarında PP lif kullanılmıştır (Şekil 2). Liflerin sadece boyları

farklı olup fiziksel ve mekanik özellikleri aynıdır ve Tablo 4'de gösterilmiştir.

Tablo 4. PP liflerin mekanik ve fiziksel özellikleri

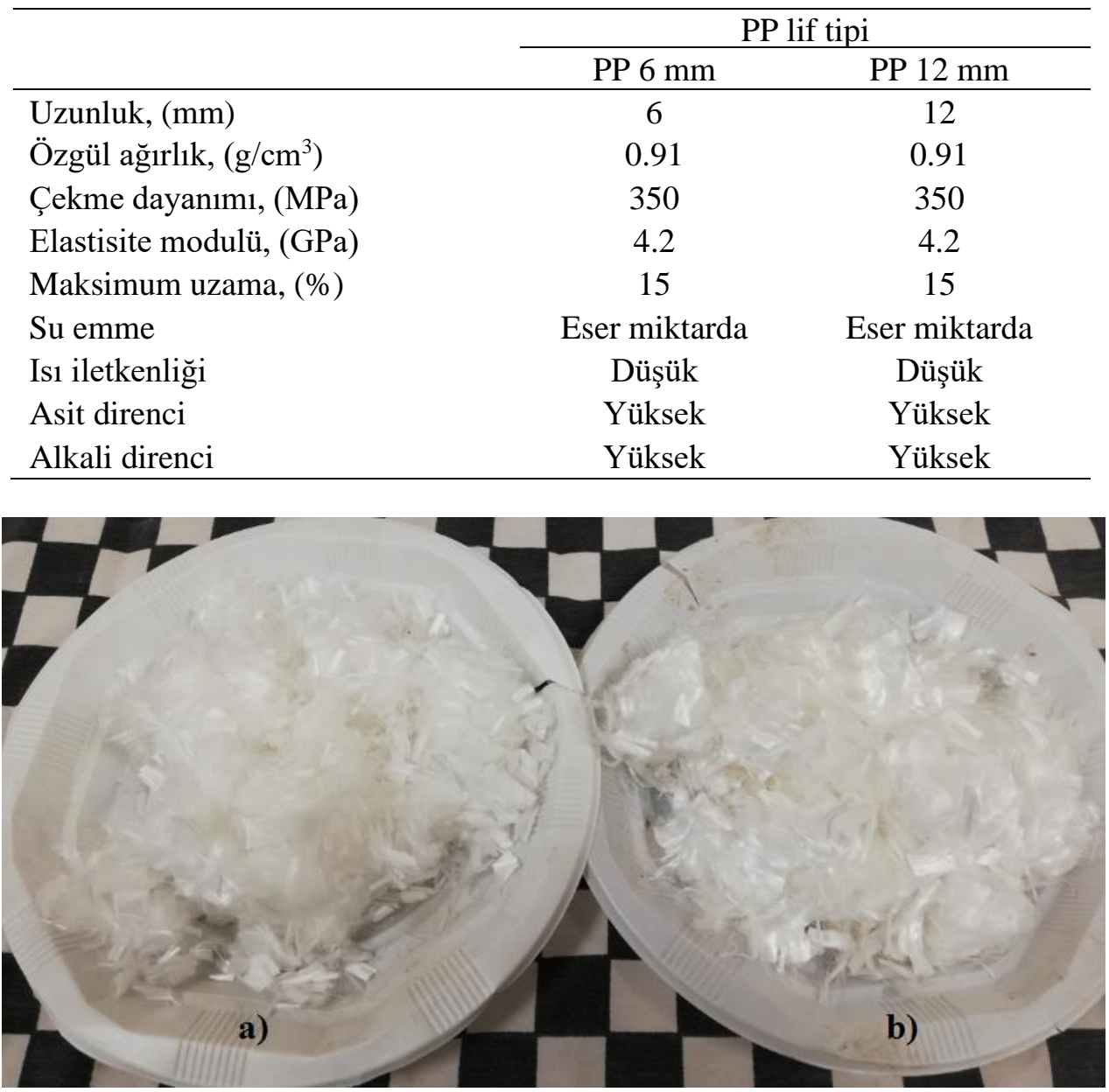

Şekil 2. Çalışmada kullanılan PP lif; a) $6 \mathrm{~mm}$, b) $12 \mathrm{~mm}$

\subsection{6. $\mathrm{HCl}$ çözeltisi}

28 günlük lifli geopolimer beton numuneleri 14 ve 28 gün boyunca $\% 5 \mathrm{HCl}$ çözeltisine maruz bırakılmıştır. Çözeltinin $\mathrm{pH}$ değeri belirli sıklıkta kontrol edilmiş ve $\mathrm{pH}$ değerinin 2.8 3.0 aralığında kalması için ihtiyaç duyuldukça çözelti yenilemesi yapılmıştır.

\subsection{Metot}

\subsubsection{Deneysel parametreler}

Geopolimer betonun üretim parametreleri ve lif oran1, literatür taraması ve ön dökümler neticesinde belirlenmiştir. Buna göre dozaj $400 \mathrm{~kg} / \mathrm{m}^{3}$, alkali aktivatör çözeltisi/bağlayıcı oranı 0.53 , alkali aktivatör konsantrasyonu $12 \mathrm{M}$ olarak seçilmiştir. Karışıma $6 \mathrm{~mm}$ ve $12 \mathrm{~mm}$ boylarında hacimce 
$\% 0.5, \% 1.0$ ve $\% 1.5$ boylarında PP lif ilave edilmiştir. Çalışmanın deneysel parametreleri Tablo 5'de özetlenmiştir.

\subsubsection{Karışım oranları}

Geopolimer beton karışımlarında YFC dozajı sabit $400 \mathrm{~kg} / \mathrm{m}^{3}$, alkali aktivatör çözeltisi/bağlayıcı oranı ise sabit 0.53 olarak seçilmiştir. $6 \mathrm{~mm}$ ve $12 \mathrm{~mm}$ boylarında PP lifler karışıma hacimce \%0.5, \%1.0 ve $\% 1.5$ oranlarında ilave edilmiştir (Tablo 5). YFC, $\mathrm{NaOH}$ çözeltisi ve liflerin hacimleri hesaplanıp $1 \mathrm{~m}^{3}$ hacimden çıkarılmış ve agregaların miktarları hesaplanmıştır. Karışım hesaplar1 için TS 802 ve TS 706 EN 12620+A1standartlarından yararlanılmıştır. Geopolimer beton numunelerin $1 \mathrm{~m}^{3}$ hacim için karışım oranları Tablo 6' da gösterilmiştir.

Tablo 5. Geopolimer beton üretim parametreleri

\begin{tabular}{|c|c|c|c|c|c|c|}
\hline \multicolumn{2}{|c|}{ Lif parametreleri } & \multicolumn{5}{|c|}{ Geopolimer beton üretim parametreleri } \\
\hline $\begin{array}{l}\text { Boy, } \\
(\mathrm{mm})\end{array}$ & $\begin{array}{l}\text { Hacimce } \\
\text { Oran, }(\%)\end{array}$ & $\begin{array}{l}\text { Dozaj, } \\
(\mathrm{kg})\end{array}$ & $\begin{array}{c}\text { Aktivatör/ } \\
\text { Bağlayıcı oranı }\end{array}$ & $\begin{array}{c}\text { Alkali } \\
\text { aktivatör }\end{array}$ & $\begin{array}{l}\text { Aktivatör } \\
\text { kons. (M) }\end{array}$ & Kür koşulu \\
\hline $\begin{array}{c}6 \\
12\end{array}$ & $\begin{array}{l}0.5 \\
1.0 \\
1.5\end{array}$ & 400 & 0.53 & $\mathrm{NaOH}$ & 12 & Lab. $\left(23^{\circ} \mathrm{C}\right)$ \\
\hline
\end{tabular}

Tablo 6. Geopolimer beton numunelerin karışım oranları

\begin{tabular}{|c|c|c|c|c|c|c|c|c|c|}
\hline \multirow{3}{*}{$\begin{array}{l}\text { Numune } \\
\text { ID }\end{array}$} & \multirow{2}{*}{\multicolumn{2}{|c|}{$\begin{array}{c}\text { Değişkenler } \\
\text { Lif Özellikleri }\end{array}$}} & \multicolumn{6}{|c|}{ Geopolimer beton bileşenleri, $\left(\mathrm{kg} / \mathrm{m}^{3}\right)$} & \multirow{3}{*}{$\begin{array}{l}\text { Teorik } \\
\text { BHA, } \\
\left(\mathrm{kg} / \mathrm{m}^{3}\right)\end{array}$} \\
\hline & & & \multirow[b]{2}{*}{ YFC } & \multirow{2}{*}{$\begin{array}{c}\mathrm{NaOH} \\
\text { çözeltisi }\end{array}$} & \multicolumn{3}{|c|}{ Agrega } & \multirow[b]{2}{*}{ PP lif } & \\
\hline & $\begin{array}{l}\text { Boy, } \\
(\mathrm{mm})\end{array}$ & $\begin{array}{c}\text { Oran, } \\
(\%)\end{array}$ & & & $0-2 \mathrm{~mm}$ & $2-4 \mathrm{~mm}$ & 4-8 mm & & \\
\hline Ref. & - & - & 400 & 212 & 708.14 & 409.68 & 501.36 & - & 2231.18 \\
\hline PP6-0.5 & & 0.5 & 400 & 212 & 702.70 & 406.53 & 497.50 & 4.55 & 2223.28 \\
\hline PP6-1.0 & 6 & 1.0 & 400 & 212 & 697.25 & 403.38 & 493.65 & 9.10 & 2215.38 \\
\hline PP6-1.5 & & 1.5 & 400 & 212 & 691.81 & 400.23 & 489.79 & 13.65 & 2207.48 \\
\hline PP12-0.5 & & 0.5 & 400 & 212 & 702.70 & 406.53 & 497.50 & 4.55 & 2223.28 \\
\hline PP12-1.0 & 12 & 1.0 & 400 & 212 & 697.25 & 403.38 & 493.65 & 9.10 & 2215.38 \\
\hline PP12-1.5 & & 1.5 & 400 & 212 & 691.81 & 400.23 & 489.79 & 13.65 & 2207.48 \\
\hline
\end{tabular}

\subsubsection{Numune hazırlanması}

Geopolimer beton numunelerinde, liflerin karışıma ilave edilme sırası homojen lif dağılımını doğrudan etkilediği için önemlidir. Daha önce yapılan çalışmalarda liflerin kuru karışıma yavaşça ilave edilmesi, daha sonra homojen kuru karışımın alkali aktivatör çözeltisine tabi tutulması önerilmiştir (Ranjbar ve Zhang; 2020; Vaidya ve Allouche, 2011; Li vd., 2005; Ganesan vd., 2015). Bu doğrultuda ilk olarak, PP lifler belirlenen oranlarda YFC'ye yavaşça ilave edilmiş ve homojen karışım elde edilinceye kadar 5 dakika boyunca karıştırılmıştır. Daha sonra agrega dahil edilmiş ve ilave 5 dakika karıştırılmıştır. Son olarak bir gün önceden hazırlanmış olan $12 \mathrm{M} \mathrm{NaOH}$ çözeltisi kuru karışıma yavaşça eklenmiş ve karıştırılmıştır (Şekil 3). Taze haldeki geopolimer beton karışımı $5 * 5 * 5 \mathrm{~cm}$ boyutlarındaki çelik kalıplara yerleştirilmiştir. Yerleştirme sırasında önemli işlenebilirlik sorunları yaşanmamıştır. Geopolimer bağlayıcı üretiminde sıklıkla tercih edilen ve en önemli dezavantajı olarak nitelendirilen 1s1l kür işlemi uygulanmamıştır. 24 saat sonra kalıptan çıkarılan numuneler asit deneylerine tabi tutulmak amaciyla deney gününe (28. Gün) kadar laboratuar koşullarında bekletilmiştir.

\subsubsection{Uygulanan deneyler}

28 günlük geopolimer beton numuneleri plastik kaplarda hazırlanmış olan \%5 $\mathrm{HCl}$ çözeltisine daldırılmıştır. Asit ortamında buharlaşma olmaması ve bunun sonucuna çözelti yoğunluğunun değişmemesi için kapların üstünün kapalı olmasına özen gösterilmiştir. 14 ve 28 günün sonunda numuneler çözeltiden çıkarılmış ve yüzeyler fırça ile silinmiştir. Asit etkisi sonucunda, geopolimer beton numunelerin basınç dayanımı, ağırlık, UPV, dış görünüş gibi fiziksel ve mekanik özelliklerindeki değişimler ASTM C 109, ASTM C 267 ve ASTM C 597 standartları ile uyumlu olarak araştırılmıştır. Ayrıca numunelerin mikro yapıları SEM analizleri ile incelenmiştir. 


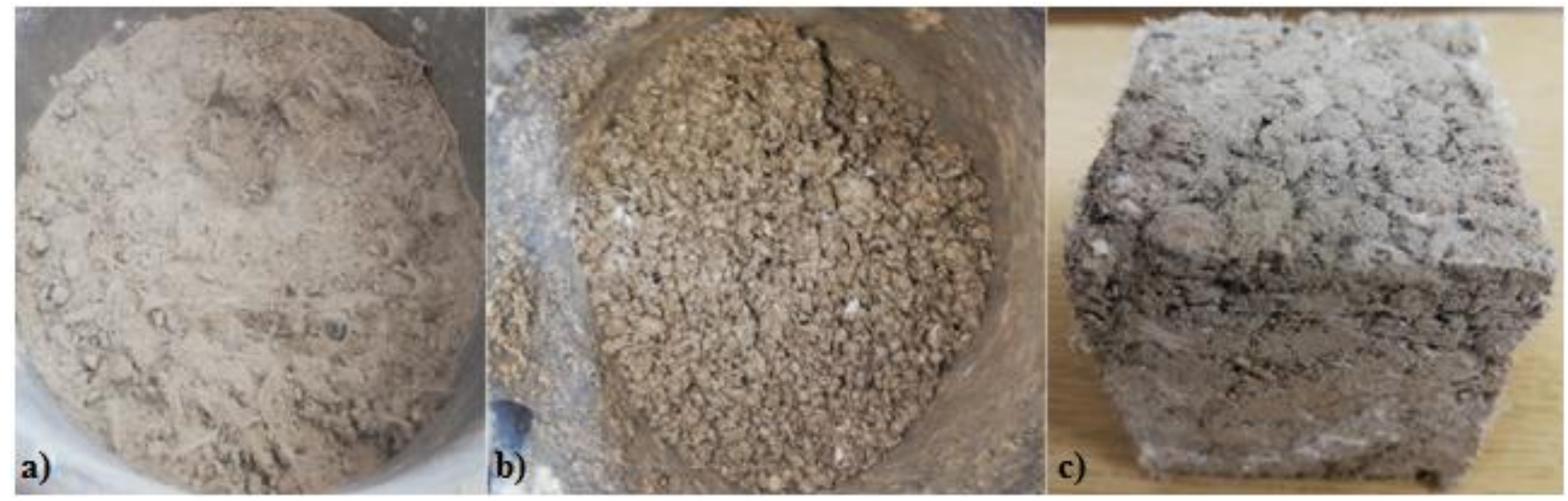

Şekil 3. Lifli geopolimer beton üretimi; a) Kuru karışım, b) Taze lifli geopolimer beton, c) Sertleşmiş lifli geopolimer beton numunesi

\section{Bulgular ve tartışma}

\subsection{Basınç dayanımı}

Geopolimer beton numunelerinin 28 günlük basinç dayanımları ile 14 ve 28 gün boyunca $\% 5 \mathrm{HCl}$ çözeltisine maruz bırakılmış numunelerin basınç dayanımları Tablo 7'de verilmiş olup Şekil 4'de grafiksel olarak gösterilmiştir. Ayrıca karşılaştırma yapabilmek amacıyla, asit etkisi sonucunda, maruz bırakılmamış numuneye kıyasla basınç dayanımında görülen azalma da Şekil 5'de verilmiştir.

Tablo 7. Geopolimer beton numunelerin asit etkisi öncesi ve sonrası basınç dayanımı değerleri

\begin{tabular}{|c|c|c|c|c|c|c|c|c|}
\hline \multirow{3}{*}{\multicolumn{2}{|c|}{ İncelenen Parametre }} & \multicolumn{7}{|c|}{ Lif İçeriği, $(\%$, Hacimce $)$} \\
\hline & & \multirow{2}{*}{$\begin{array}{c}\text { Ref. } \\
0\end{array}$} & \multicolumn{3}{|c|}{ PP $6 \mathrm{~mm}$} & \multicolumn{3}{|c|}{ PP $12 \mathrm{~mm}$} \\
\hline & & & 0.5 & 1.0 & 1.5 & 0.5 & 1.0 & 1.5 \\
\hline \multirow{3}{*}{$\begin{array}{c}\text { Basınç Dayanımı, } \\
(\mathrm{MPa})\end{array}$} & 28 Günlük Referans & 39.9 & 47.6 & 41.1 & 36.6 & 45.4 & 40.3 & 31.8 \\
\hline & 14 Gün $\mathrm{HCl}$ Sonrası & 32.1 & 44.7 & 36.7 & 27.2 & 42.3 & 35.4 & 24.1 \\
\hline & 28 Gün HCl Sonras1 & 25.9 & 41.1 & 32.8 & 25.1 & 37.2 & 30.3 & 20.6 \\
\hline \multirow{2}{*}{$\begin{array}{l}\text { Dayanımındaki } \\
\text { Azalma, }(\%)\end{array}$} & 14 Gün HCl Sonras1 & 19.5 & 6.1 & 10.7 & 25.7 & 6.8 & 12.2 & 24.2 \\
\hline & 28 Gün HCl Sonras1 & 35.1 & 13.7 & 20.2 & 31.4 & 18.1 & 24.8 & 35.2 \\
\hline
\end{tabular}

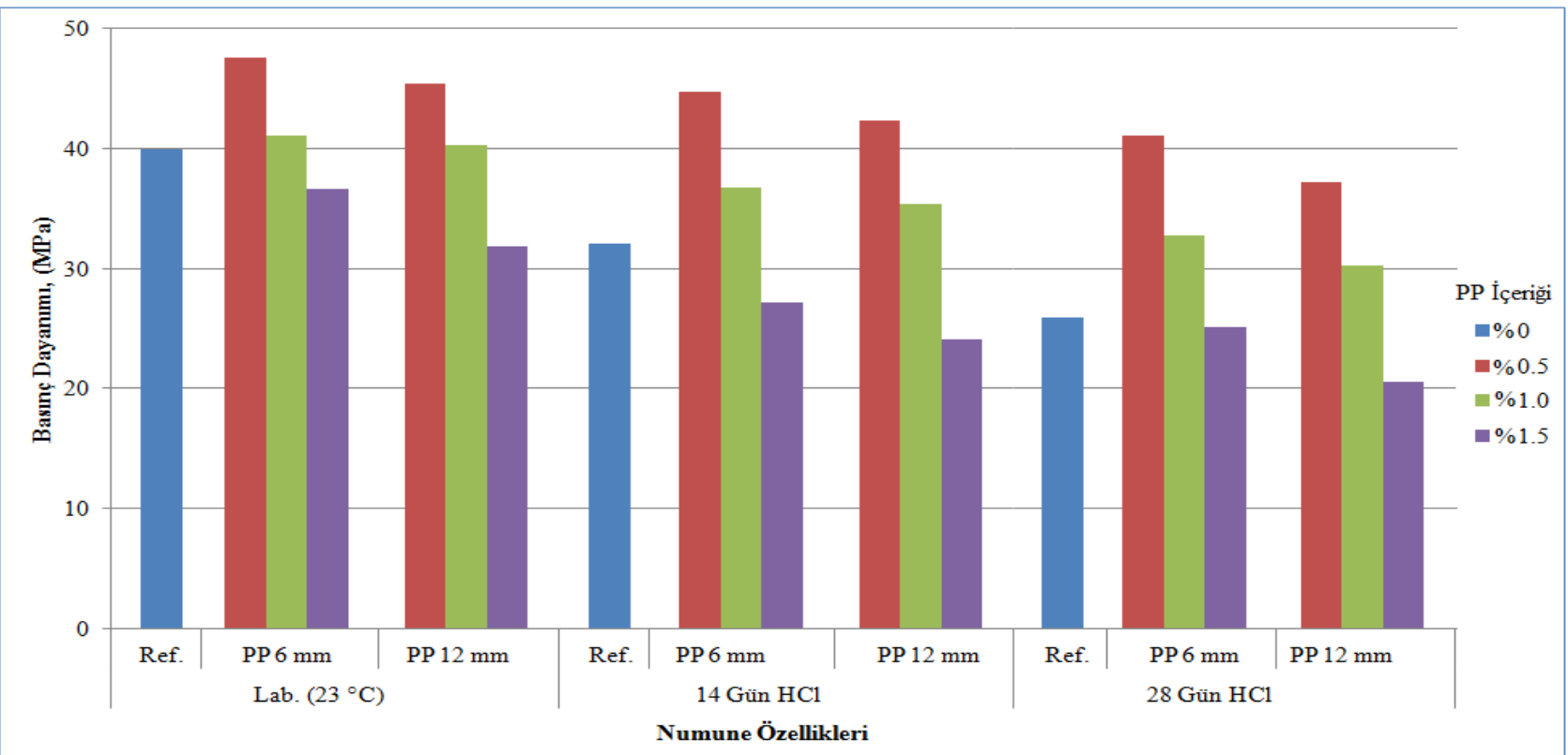

Şekil 4. PP lif boyunun ve içeriğinin geopolimer betonların asit etkisi öncesi ve sonrası basınç dayanımlarına etkisi 


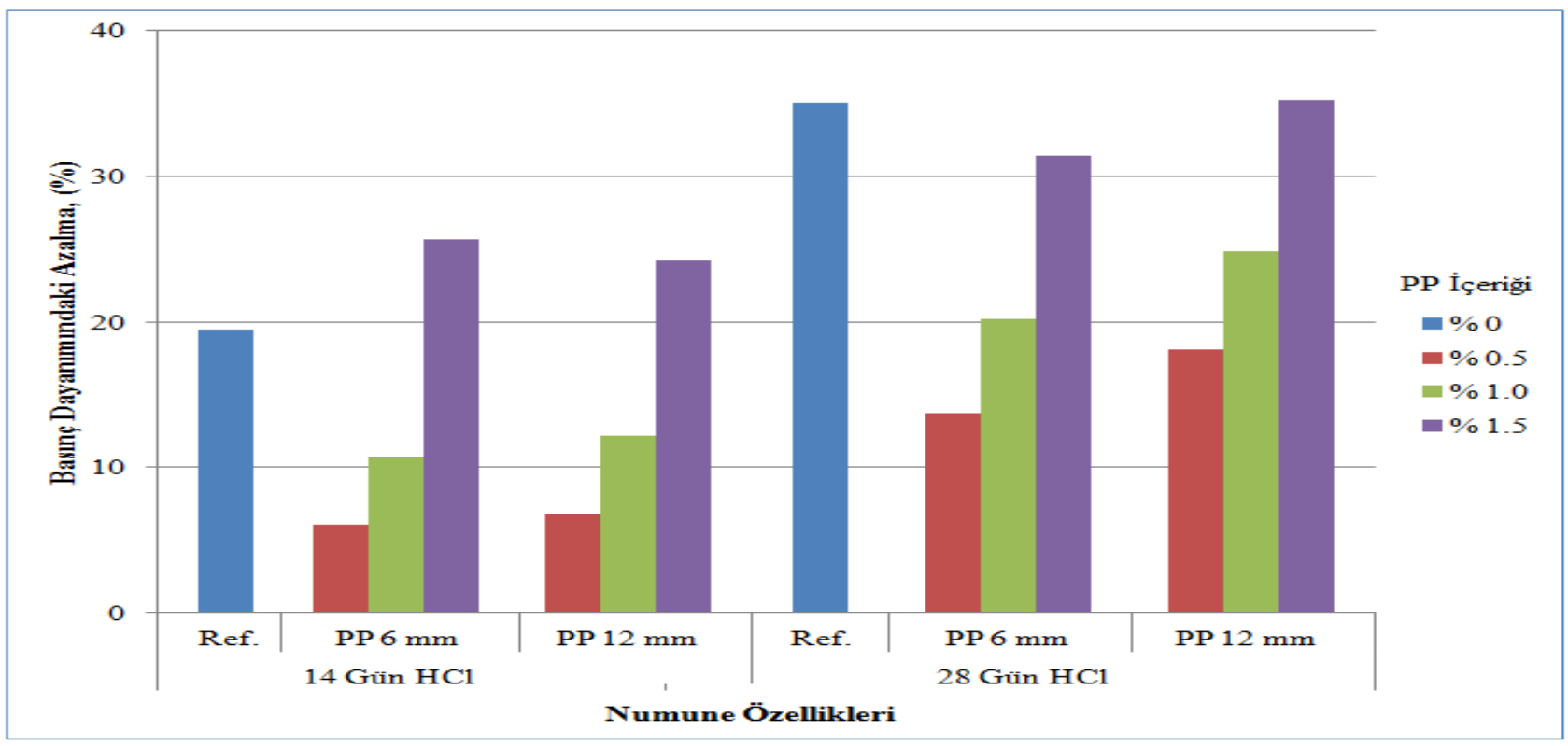

Şekil 5. Geopolimer betonların asit etkisi sonucunda, maruz bırakılmamış numuneye kıyasla basınç dayanımında görülen azalma

Geopolimer beton numunelerin asit etkisi öncesi araştırma bulguları incelendiğinde, hacimce $\% 0.5$ oranında lif katkısının basınç dayanımını arttırdığı tespit edilmiştir. Bu durum, lif katkısının çatlak oluşumunu engelleyen köprü görevi görmesi ve böylelikle bağlayıcı fazda daha yoğun bir mekanik bağ oluşumu sayesinde olabilir (Dawood ve Ramli, 2011; Sabu ve Karthi, 2018). Artan lif içeriğinin işlenebilirlik problemlerine yol açması nedeniyle basınç dayanımını düşürdüğü tespit edilmiştir. Azalan işlenebilirlik, lifler arasındaki bağlantıyı zayıflatır, matris içerisinde boşluklara neden olur, ara yüzey geçiş bölgelerinde kusurlara yol açar ve böylelikle basınç dayanımında azalmaya neden olur (Ranjbar ve Zhang, 2020; Zollo, 1997; Martinie vd. 2010; Zhang vd., 2018; Sukontasukkul vd., 2018; Moradikhou vd., 2020). Optimum oranda lif katkısının geopolimer betonların basınç dayanımını iyileştirdiği çeşitli çalışmalarda doğrulanmıştır (Ranjbar ve Zhang, 2020; Moradikhou vd., 2020; Mohseni, 2018). 6 $\mathrm{mm}$ lif boyu bütün içeriklerde daha yüksek basınç dayanımı sergilemiştir. Bu durum lif boyu arttıkça liflerin homojen dağılmasının daha zor olmasından kaynaklanmış olabilir (Wang vd., 2020).

Geoplimer betonların asit etkisi sonrası araştırma bulguları incelendiğinde, asit etkisi öncesi basınç dayanımları ile uyumlu olarak \%0.5 oranında lif katkısının asit etkisine daha dayanıklı olduğu tespit edilmiştir. Bu durum yukarıda da bahsedildiği üzere optimum oranda lif katkısının çatlak gelişimini engellemesi ve böylelikle asit çözeltisinin beton bünyesine nüfuz etmesinin zorlaşması nedeniyle olmuş olabilir. Buna karşıllık $\% 1.5$ oranında lif katkısının asit direncini düşürmesi ise, artan lif içeriğinin boşluklu yapıya yol açması ve böylelikle asit çözeltisinin içyapıya daha kolay ulaşabilmesinden kaynaklı olabilir. Bununla birlikte, \%1.0 oranında lif kullanılması basınç dayanımında kayda değer bir iyileşmeye neden olmazken, asit etkisi sonrası kalan basınç dayanımlarında daha az düşüşe neden olmuştur (Şekil 5). $6 \mathrm{~mm}$ boyunda PP lif kullanılması 12 mm'ye kıyasla daha etkili sonuçlar vermiştir. Optimum oranda lif içeren geopolimer betonların asit dirençlerinin yüksek olduğu çeşitli çalışmalarda doğrulanmıştır (Ranjbar ve Zhang, 2020; Ganesan vd., 2015; Yunsheng vd., 2008).

\subsection{UPV değerleri}

Geopolimer beton numunelerinin asit etkisi öncesi ve sonrası UPV değerleri Tablo 8'de verilmiş olup Şekil 6'da verilmiştir. Ayrıca basınç dayanımı ile UPV değerleri arasındaki ilişki Şekil 7'de gösterilmiştir. 
Tablo 8. Geopolimer beton numunelerin asit etkisi öncesi ve sonrası UPV değerleri

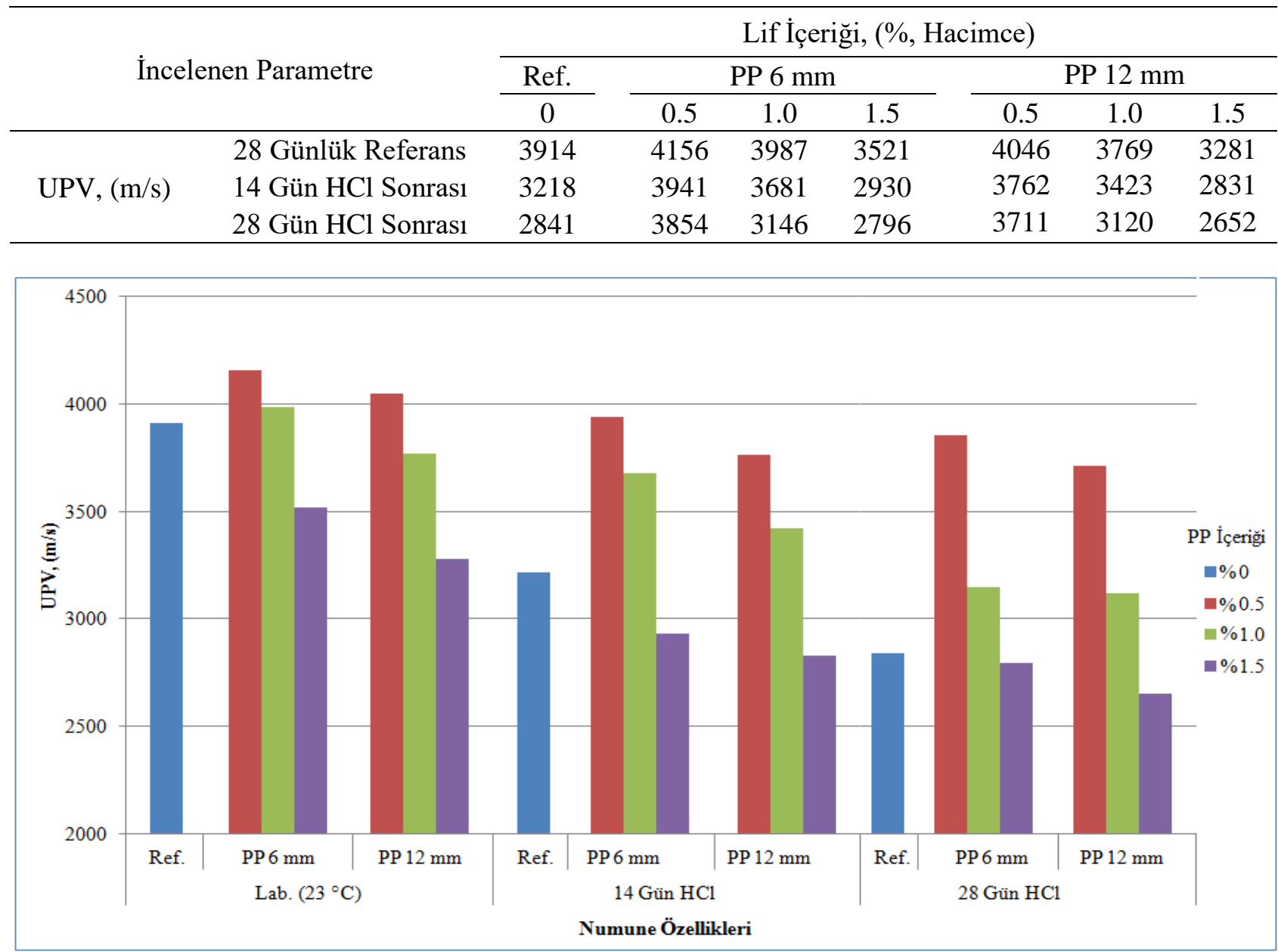

Şekil 6. Geopolimer beton numunelerin UPV değerleri

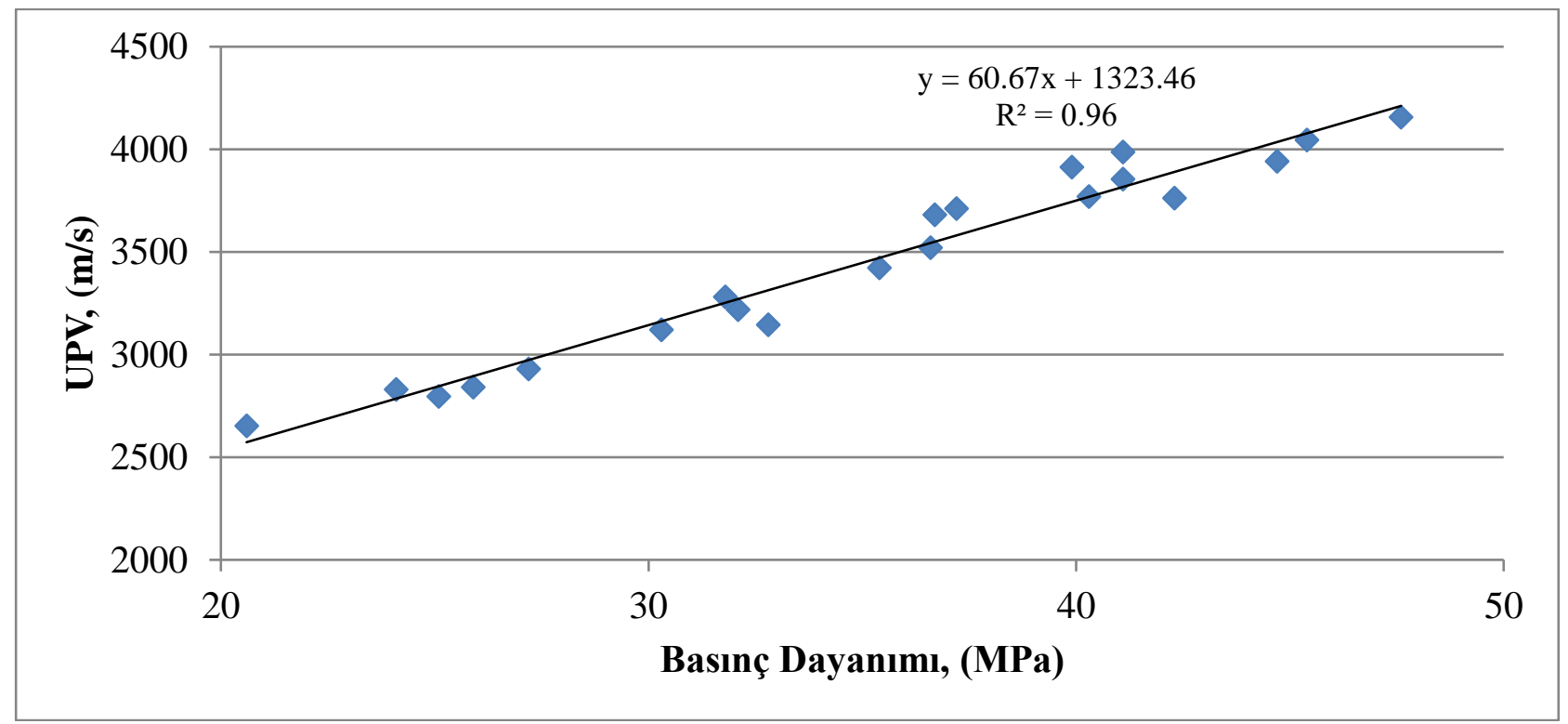

Şekil 7. Geopolimer beton numunelerin basınç dayanımı ile UPV değerleri arasındaki ilişki

Geopolimer beton numunelerin UPV değerleri, basınç dayanımı bulguları ile uyumlu olarak lif içeriği arttıkça düşmüştür. Asit etki süresi arttıkça
UPV değerleri beklendiği gibi düşmüştür. $\% 0.5$ oranında lif katkısı matris yapıyı güçlendirdiği için UPV değerleri artmış, buna karşı1ık \% 1.5 oranında 
lif ilavesi boşluklu yapı oluşturması nedeniyle UPV değerleri düşmüştür. Ayrıca asit etkisi sonucunda bağlayıcı jellerin tahrip olması, boşluklu yapının artmasına ve UPV değerlerinin düşmesine neden olmuştur. Deneysel çalışmalar sonucunda geopolimer beton numunelerin basinç dayanımı ile UPV değerleri arasında iyi bir ilişki $\left(\mathrm{R}^{2}=0.96\right)$ elde edilmiştir. Deneysel çalışmalar sonucunda elde edilen UPV değerleri daha önce yapılan çalışmalarda elde edilen bulgular ile örtüşmektedir (Kantarc1 vd., 2019; Ghosh vd., 2018; Yadollahi vd., 2015; Noushini ve Castel, 2016).

\section{3. Ăgırlık değişimi}

Geopolimer beton numunelerinin asit etkisi sonras1 ağırlığında görülen azalma Tablo 9'da verilmiş olup Şekil 8'de gösterilmiştir.

Tablo 9. Geopolimer beton numunelerin asit etkisi sonrası ağırlık kayıpları

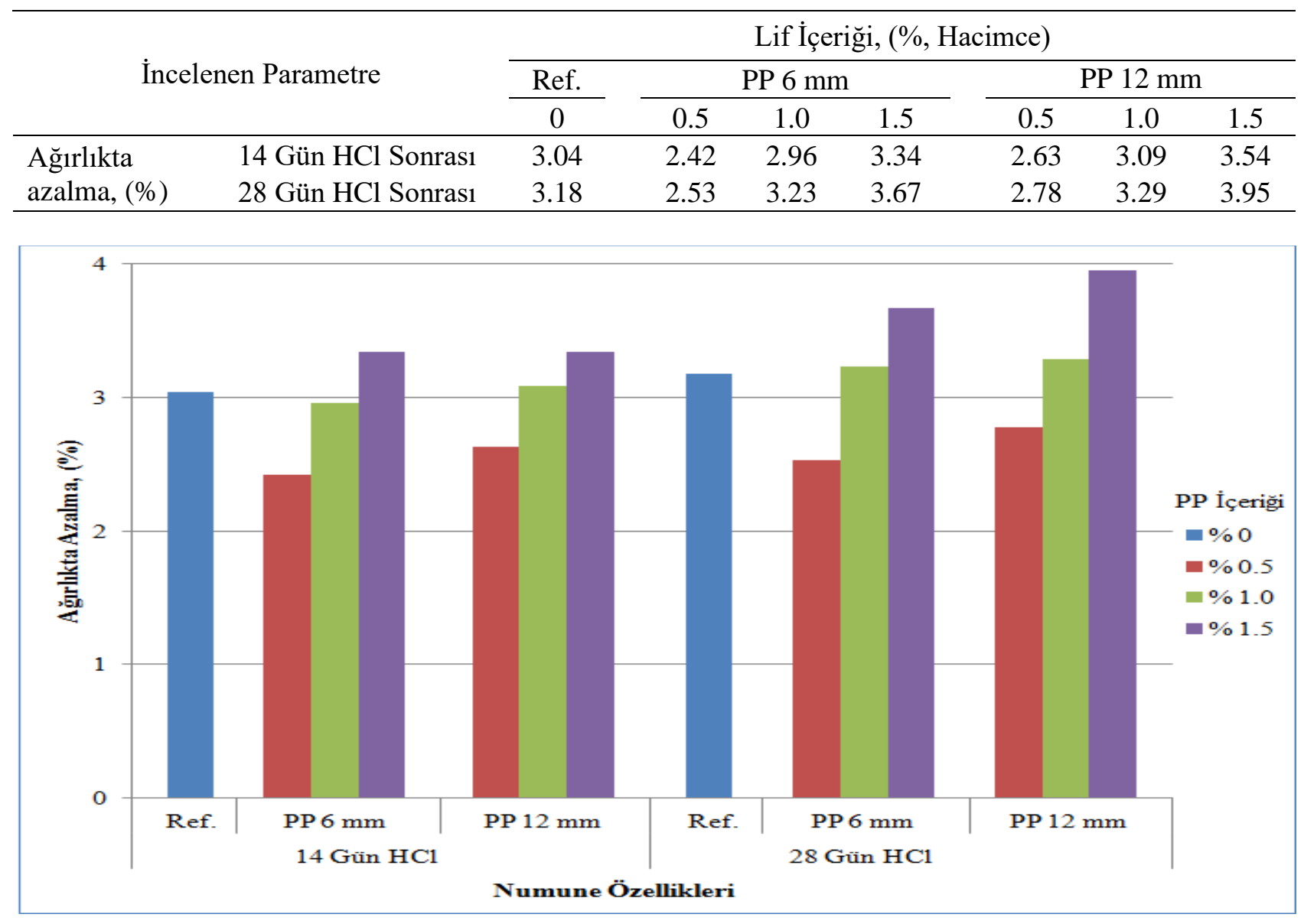

Şekil 8. Geopolimer beton numunelerin asit etkisi sonrası ağırlık kayıpları

Asit etkisi sonucunda geopolimer betonların ağırlıkları beklendiği gibi düşmüştür. Asit etki süresi arttıkça ağırlık kayıpları da artmıştır. Asit etkisi sonucunda meydana gelen ağırlık kayıpları geopolimer jel matrisindeki alüminosilikat bağlarının kırılmasından kaynaklanmaktadır (Djobo vd., 2016; Bakharev, 2005). Ancak \%0.5 oranında lif katkısı, çatlak gelişimini engellemesi ve böylelikle asit çözeltisinin beton bünyesine daha az nüfuz etmesi nedeniyle ağırlık kayıplarını azaltmıştır. Geopolimer betonların asit ortamlarında ağıllık kayıplarının, normal Portland çimentolu betonlara kıyasla daha az olduğu çeşitli çalışmalarda doğrulanmıştır (Ariffin vd., 2013;
Kim vd., 2014; Davidovits, 1991; Huseien vd., 2017; Bhutta vd., 2014). Bu çalışmada ise hacimce $\% 0.5$ oranında lif katkısının asit ortamlarında ağırlık kayıplarını daha da azalttığ 1 ortaya çıkarılmıştır. Lif içeriği ve lif boyu arttıkça ağırlık kayıpları da artmıştır.

\subsection{Görsel inceleme}

Geopolimer beton numunelerinin 14 ve 28 gün boyunca $\% 5 \mathrm{HCl}$ çözeltisine maruz bırakıldıktan sonraki görünümleri Şekil 9'da verilmiştir. 


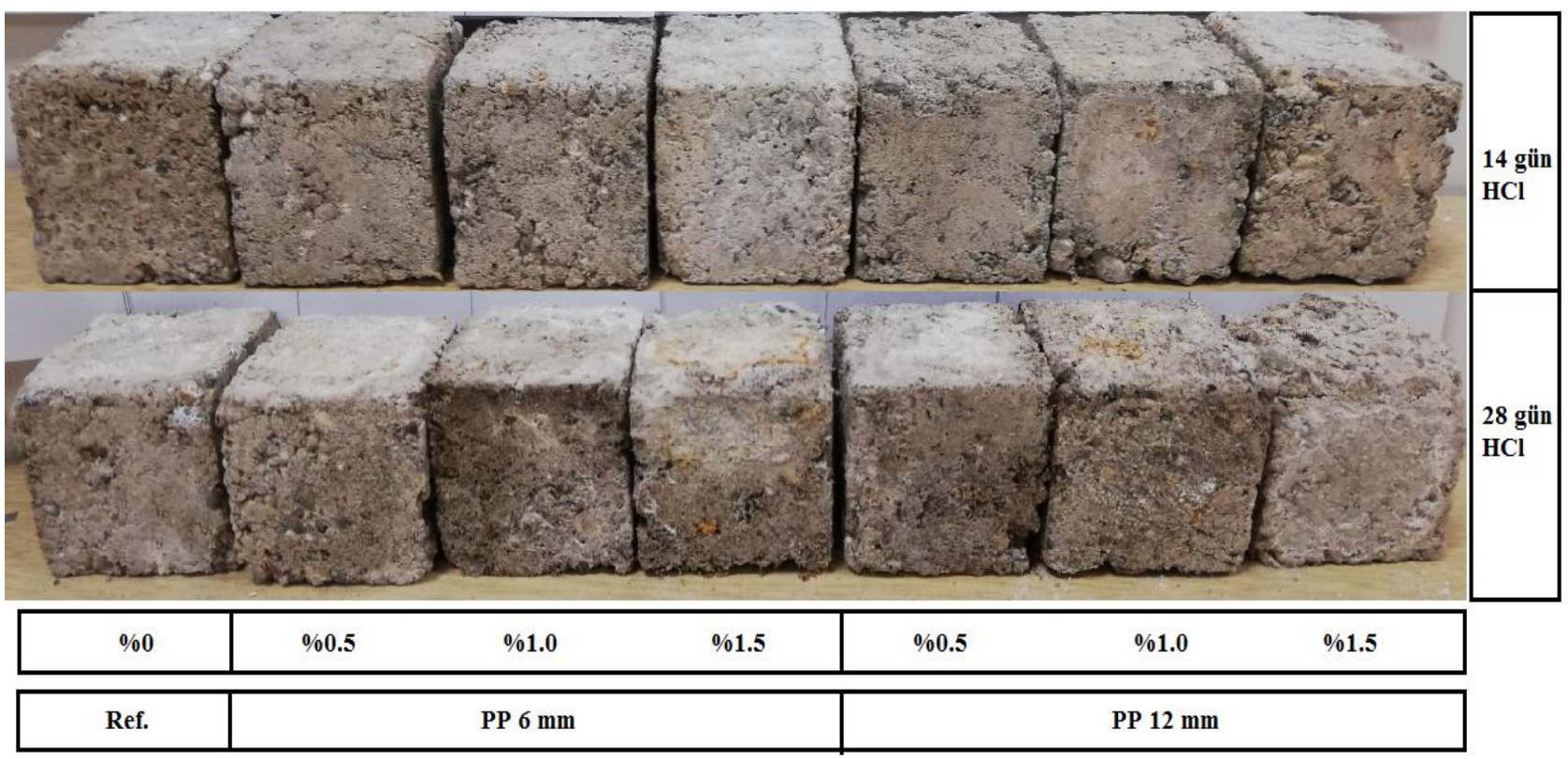

Şekil 9. Geopolimer numunelerin asit etkisi sonrası görünümleri

Geopolimer beton numunelerde asit etkisi sonucunda yüzeyde aşınmalar ve köşelerde kırılmalar meydana gelmiştir. Özellikler \%1.5 oranında lif içeriğine sahip geopolimer betonlarda ağırlık kayıpları ile uyumlu olarak daha fazla tahribat gözlenmiştir. Ayrıca numunelerin yüzeyinde yer yer beyaz renkli tabakalanmalar tespit edilmiştir. Benzer oluşumlar Guo vd. (2016) tarafindan $\% 5 \mathrm{HCl}$ çözeltisine maruz bırakılmış geopolimer betonlarda da rapor edilmiştir. $\mathrm{Bu}$ durum geopolimer jel tabakası ile asit çözeltisi arasında oluşan çökelme reaksiyonlarından kaynaklı olabilir (Djobo vd., 2016).

\subsection{Mikroyapı analizi}

Geopolimer beton numunelerinin 14 gün $\% 5 \mathrm{HCl}$ çözeltisine maruz bırakıldıktan sonraki SEM görüntüleri Şekil 10'da verilmiştir.

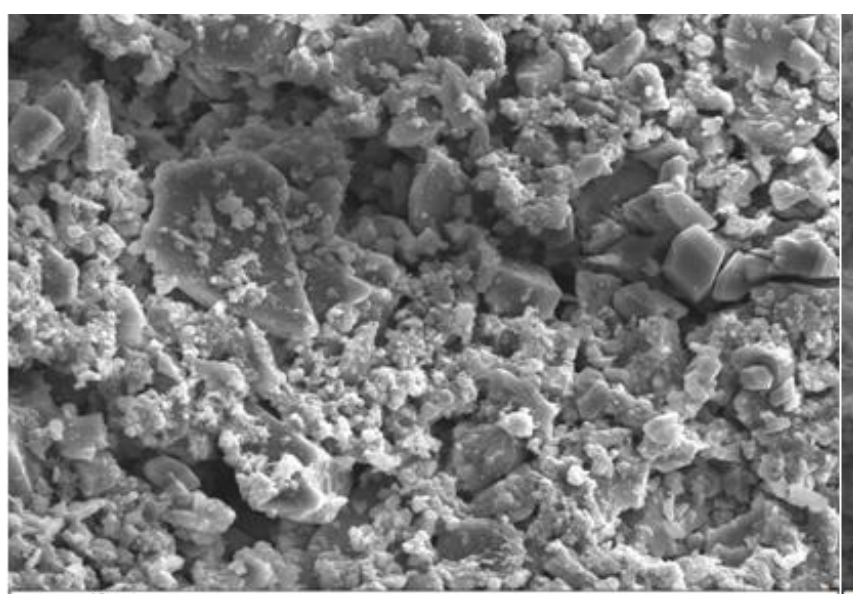

a)

$\operatorname{Mag}=2.50 \mathrm{KX}$

EHT $=20.00 \mathrm{kV}$ Signal $A=$ SET $\quad W D=13 \mathrm{~mm}$

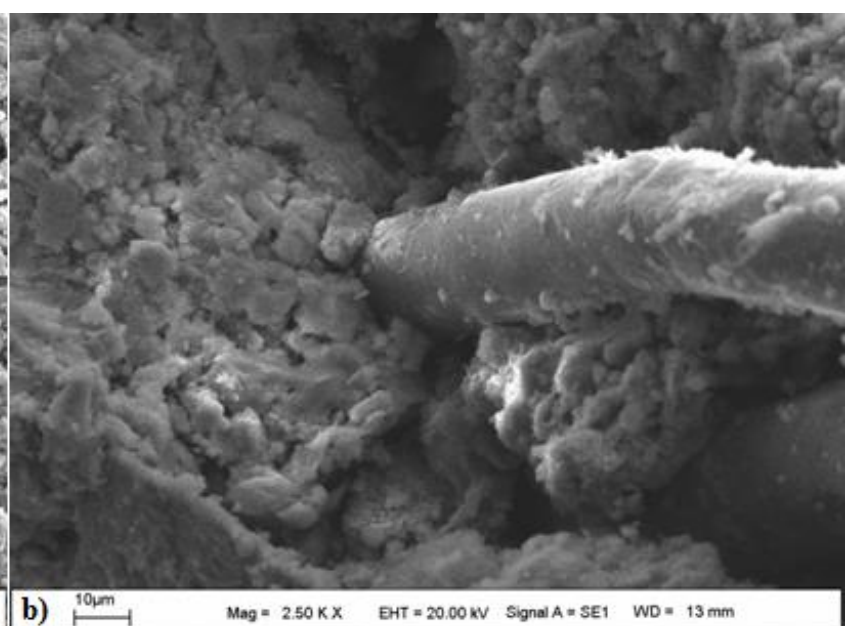

Şekil 10. 14 gün $\% 5 \mathrm{HCl}$ etkisine maruz bırakılmış geopolimer beton numunelerin SEM görüntüleri, a) Lif katksız referans numune, b) $6 \mathrm{~mm}$ boyunda \%0.5 oranında lif katkılı numune

SEM görüntüleri incelendiğinde optimum oranda lif katkısının bağlayıcı fazda oluşturduğu köprü etkisi sayesinde daha yoğun ve kompakt bir mikro yapıya neden olduğu, buna karşılık lif katkısız numunelerin ise göreceli olarak daha boşluklu yapıda olduğu görülmüştür. $\mathrm{Bu}$ durum basınç dayanımı ve ağırlıklardaki düşüş bulguları ile örtüşmektedir.

\section{Sonuç ve öneriler}

Bu çalışmada, laboratuar koşullarında üretilmiş geopolimer betonların asit direncine lif boyunun ve 
içeriğinin etkisi araştırılmıştır. Bu amaçla 6 ve 12 $\mathrm{mm}$ boylarında PP lif, hacimce $\% 0.5, \% 1.0$ ve $\% 1.5$ oranlarında ilave edilmiştir. Araştırma bulguları şu şekilde özetlenebilir:

- Hacimce $\% 0.5$ oranında lif katkısı, çatlak oluşumunu engelleyen köprü görevi görmesi ve böylelikle bağlayıcı fazda daha yoğun bir mekanik bağ oluşturması sayesinde geopolimer betonların asit öncesi ve sonras1 basınç dayanımını arttırmıştır.

- Hacimce \%1.5 oranında lif katkısı, artan lif içeriğinin boşluklu yapıya yol açması ve böylelikle asit çözeltisinin içyapıya daha kolay ulaşabilmesi nedeniyle asit direncini düşürmüştür.

- $6 \mathrm{~mm}$ boyunda PP lif kullanılmasi homojen dağılmasının daha kolay olması nedeniyle 12 mm'ye kıyasla daha etkili sonuçlar vermiştir

- UPV değerleri, basınç dayanımı bulguları ile uyumlu olarak lif içeriği arttıkça düşmüştür. Basınç dayanımı ile UPV değerleri arasında iyi bir ilişki $\left(\mathrm{R}^{2}=0.96\right)$ elde edilmiştir.

- Hacimce \%0.5 oranında lif katkısı, çatlak gelişimini engellemesi ve böylelikle asit çözeltisinin beton bünyesine daha az nüfuz etmesi nedeniyle ağırlık kayıplarını azaltmıştır.

- Hacimce \%1.5 lif içeren geopolimer beton numunelerinin asit etkisi sonucunda yüzeyinde aşınmalar ve köşelerde kırılmalar meydana gelmiştir. Ayrica numunelerin yüzeyinde çökelme reaksiyonları nedeniyle yer yer beyaz renkli tabakalanmalar tespit edilmiştir.

- Hacimce \%0.5 lif katkısının bağlayıcı fazda oluşturduğu köprü etkisi sayesinde daha yoğun ve kompakt bir mikro yapıya neden olduğu tespit edilmiştir.

Yapılan deneysel çalışmalar sonucunda hacimce $\% 0.5$ lif katkısının, \%1.0 ve \%1.5 oranlarına kıyasla daha etkili olduğu tespit edilmiştir. Lifli geopolimer betonların yaygın bir şekilde kullanılabilmesi için çeşitli lif türlerinin ve oranlarının farklı çevresel koşullar altındaki etkisinin ayrıntılı bir şekilde ortaya çıkarılmasına ihtiyaç vardır. Sürdürülebilir yapı malzemesi olan geopolimer betonların kullanılması çevresel ve ekonomik birçok avantaj sağlayacaktır.

\section{Kaynaklar}

Ariffin, M. A. M., Bhutta, M. A. R., Hussin, M. W., Tahir, M. M. and Aziah, N. (2013). Sulfuric acid resistance of blended ash geopolymer concrete. Construction and building materials, 43, 80-86. https://doi.org/10.1016/j.conbuildmat.2013.01.0 18

Assi, L.N., Deaver, E.E. and Ziehl, P. (2018). Effect of source and particle size distribution on the mechanical and microstructural properties of fly ash-based geopolymer concrete. Construction and Building Materials, 167, 372-380. https://doi.org/10.1016/j.conbuildmat.2018.01.1 93

ASTM C109. (2020). Standard Test Method for Compressive Strength of Hydraulic Cement Mortars (Using 2-in. or $\left[\begin{array}{lll}50 & \mathrm{~mm}\end{array}\right]$ Cube Specimens). ASTM International, West Conshohocken, PA.

ASTM C267-20. (2020). Standard Test Methods for Chemical Resistance of Mortars, Grouts, and Monolithic Surfacings and Polymer Concretes. ASTM International, West Conshohocken, PA.

ASTM C597-16. (2016). Standard Test Method for Pulse Velocity Through Concrete, ASTM International, West Conshohocken, PA.

Aswani, E. and Karthi, L. (2017). A literature review on fiber reinforced geopolymer concrete. International Journal of Scientific \& Engineering Research, 8(2), 408-411.

Bakharev, T. (2005). Resistance of geopolymer materials to acid attack. Cement and concrete research, 35(4), 658-670. https://doi.org/10.1016/j.cemconres.2004.06.00 5

Bakharev, T., Sanjayan, J. G. and Cheng, Y. B. (2003). Resistance of alkali-activated slag concrete to acid attack. Cement and Concrete research, 33(10), 1607-1611. https://doi.org/10.1016/S0008-8846(03)00125$\mathrm{X}$

Beddoe, R. E. And Dorner, H. W. (2005). Modelling acid attack on concrete: Part I. The essential mechanisms. Cement and concrete research, 35(12), 2333-2339. https://doi.org/10.1016/j.cemconres.2005.04.00 2

Bhutta, M. A. R., Hussin, W. M., Azreen, M. and Tahir, M. M. (2014). Sulphate resistance of geopolymer concrete prepared from blended waste fuel ash. Journal of Materials in Civil Engineering, 26(11), 04014080. https://doi.org/10.1061/(ASCE)MT.19435533.0001030

Comrie, D.C. and Davidovits, J. (1988). Long Term Durability of Hazardous Toxic and Nuclear Waste Disposals, Proceedings of Geopolymer88; First European Conference on Soft Mineralurgy, Compiegne. 
Damilola, O.M. (2013). Syntheses, characterization and binding strength of geopolymers: a review. International Journal of Materials Science and Applications, 2(6), 185-193. doi: 10.11648/j.ijmsa.20130206.14

Davidovits, J. (1991). Geopolymers: inorganic polymeric new materials. Journal of Thermal Analysis and calorimetry, 37(8), 1633-1656. https://doi.org/10.1007/bf01912193

Davidovits, J. (1993). Geopolymer cements to minimise carbon-dioxide greenhousewarming. Ceramic Transactions, 37, 165-182.

Davidovits, J. (1994). High-Alkali Cements for 21st Century Concretes. ACI Special Publication, 144, 383-398.

Davidovits, J. (2008). Geopolymer Chemistry and Applications, Institut Géopolymère, SaintQuentin.

Davidovits, J. (2011). Geopolymer Chemistry and Applications, third ed. Institute of Geopolymere.

Davidovits, J., Comrie, D.C., Paterson, J.H. and Ritcey, D.J. (1990). Geopolymeric concretes for environmental protection, Concrete International, 12(7), 30-40.

Dawood, E. T. and Ramli, M. (2011). Contribution of hybrid fibers on the properties of high strength concrete having high workability. Procedia Engineering, $\quad 14, \quad 814-820$. https://doi.org/10.1016/j.proeng.2011.07.103

Djobo, J. N. Y., Elimbi, A., Tchakouté, H. K. and Kumar, S. (2016). Mechanical properties and durability of volcanic ash based geopolymer mortars. Construction and Building Materials, 124 ,

606-614. https://doi.org/10.1016/j.conbuildmat.2016.07.1 41

Duxson, P., Provis, J. L., Lukey, G. C. and Van Deventer, J. S. (2007). The role of inorganic polymer technology in the development of 'green concrete'. Cement and Concrete Research, 37(12), 1590-1597. https://doi.org/10.1016/j.cemconres.2007.08.01 8

El-Gamal, S.M.A. and Selim, F.A. (2017). Utilization of some industrial wastes for eco-friendly cement production. Sustainable Materials and Technologies, 12, 9-17. https://doi.org/10.1016/j.susmat.2017.03.001

Ganesan, N., Abraham, R. and Raj, S. D. (2015). Durability characteristics of steel fibre reinforced geopolymer concrete. Construction and Building Materials,

93,

471-476. https://doi.org/10.1016/j.conbuildmat.2015.06.0 14

Ganesh, A.C. and Muthukannan, M. (2021). Development of high performance sustainable optimized fiber reinforced geopolymer concrete and prediction of compressive strength. Journal of Cleaner Production, 282, 124543. https://doi.org/10.1016/j.jclepro.2020.124543

Ghosh, R., Sagar, S. P., Kumar, A., Gupta, S. K. and Kumar, S. (2018). Estimation of geopolymer concrete strength from ultrasonic pulse velocity (UPV) using high power pulser. Journal of building engineering, 16, 39-44. https://doi.org/10.1016/j.jobe.2017.12.009

Guo, C. M., Wang, K. T., Liu, M. Y., Li, X. H. and Cui, X. M. (2016). Preparation and characterization of acid-based geopolymer using metakaolin and disused polishing liquid. Ceramics International, 42(7), 9287-9291. https://doi.org/10.1016/j.ceramint.2016.02.073

Huseien, G. F., Mirza, J., Ismail, M., Ghoshal, S. K. and Hussein, A. A. (2017). Geopolymer mortars as sustainable repair material: A comprehensive review. Renewable and Sustainable Energy Reviews, 80, 54-74. https://doi.org/10.1016/j.rser.2017.05.076

Kajaste, R. and Hurme, M. (2016). Cement industry greenhouse gas emissions-management options and abatement cost. Journal of Cleaner Production, 112, 4041-4052. https://doi.org/10.1016/j.jclepro.2015.07.055

Kantarc1, F., Türkmen, İ. and Ekinci, E. (2019). Optimization of production parameters of geopolymer mortar and concrete: A comprehensive experimental study. Construction and Building Materials, 228, 116770. https://doi.org/10.1016/j.conbuildmat.2019.1167 70

Kim, Y. Y., Lee, B. J., Saraswathy, V. and Kwon, S. J. (2014). Strength and durability performance of alkali-activated rice husk ash geopolymer mortar. The Scientific World Journal, 2014. https://doi.org/10.1155/2014/209584

Kwasny, J., Aiken, T. A., Soutsos, M. N., McIntosh, J. A. and Cleland, D.J. (2018). Sulfate and acid resistance of lithomarge-based geopolymer mortars. Construction and Building Materials, 166 , 537-553. https://doi.org/10.1016/j.conbuildmat.2018.01.1 29

Li, Z., Zhang, Y. And Zhou, X. (2005). Short fiber reinforced geopolymer composites manufactured by extrusion. Journal of materials in civil engineering, $\quad 17(6)$,

624-631. 
DOI:10.1061/(ASCE)08991561(2005)17:6(624)

Malhotra, V.M. (1999). Making Concrete "Greener" With Fly Ash. Concrete International, 21(5), 6166.

Martinie, L., Rossi, P. and Roussel, N. (2010). Rheology of fiber reinforced cementitious materials: classification and prediction. Cement and concrete research, 40(2), 226-234. https://doi.org/10.1016/j.cemconres.2009.08.03 2

Meyer, C. (2009). The greening of the concrete industry. Cement and Concrete Composites, 31(8), 601605.

https://doi.org/10.1016/j.cemconcomp.2008.12. 010

Mohseni, E. (2018). Assessment of $\mathrm{Na} 2 \mathrm{SiO} 3$ to $\mathrm{NaOH}$ ratio impact on the performance of polypropylene fiber-reinforced geopolymer composites. Construction and Building Materials, 186, 904-911. https://doi.org/10.1016/j.conbuildmat.2018.08.0 32

Moradikhou, A.B., Esparham, A. and Avanaki, M.J. (2020). Physical \& mechanical properties of fiber reinforced metakaolin-based geopolymer concrete. Construction and Building Materials, 25,118965

https://doi.org/10.1016/j.conbuildmat.2020.1189 65

Noushini, A. and Castel, A. (2016). The effect of heatcuring on transport properties of low-calcium fly ash-based geopolymer concrete. Construction and Building Materials, 112, 464-477. https://doi.org/10.1016/j.conbuildmat.2016.02.2 10

Palomo, A., Blanco-Varela, M. T., Granizo, M. L., Puertas, F., Vazquez, T. and Grutzeck, M. W. (1999). Chemical stability of cementitious materials based on metakaolin. Cement and Concrete Research, 29(7), 997-1004. https://doi.org/10.1016/S0008-8846(99)00074-5

Ranjbar, N., and Zhang, M. (2020). Fiber-reinforced geopolymer composites: A review. Cement and Concrete Composites, 107, 103498. https://doi.org/10.1016/j.cemconcomp.2019.103 498

Reed, M., Lokuge, W. and Karunasena, W. (2014). Fibre-reinforced geopolymer concrete with ambient curing for in situ applications. Journal of materials science, 49(12), 4297-4304. https://doi.org/10.1007/s10853-014-8125-3

Sabu, A. and Karthi, L. (2018). A review on strength properties of fibre and hybrid fibre reinforced geopolymer concrete. International Research Journal of Engineering and Technology, 5, 16861690.

Sata, V., Sathonsaowaphak, A. and Chindaprasirt, P. (2012). Resistance of lignite bottom ash geopolymer mortar to sulfate and sulfuric acid attack. Cement and Concrete Composites, 34(5), 700-708.

https://doi.org/10.1016/j.cemconcomp.2012.01. 010

Scrivener, K.L., John, V.M. and Gartner, E.M. (2018). Eco-efficient cements: potential economically viable solutions for a low-CO2 cement-based materials industry. Cement and Concrete Research, $\quad 114, \quad 2-26$. https://doi.org/10.1016/j.cemconres.2018.03.01 5

Shi, X.S., Wang, Q.Y., Zhao, X.L. and Collins, F. (2012). Discussion on properties and microstructure of geopolymer concrete containing fly ash and recycled aggregate. Advanced Materials Research, 450-451, 15771583.

https://doi.org/10.4028/www.scientific.net/AM R.450-451.1577

Singh, N.B. (2018). Fly ash-based geopolymer binder: A future construction material. Minerals, 8(7), 299. https://doi.org/10.3390/min8070299

Sukontasukkul, P., Pongsopha, P., Chindaprasirt, P. and Songpiriyakij, S. (2018). Flexural performance and toughness of hybrid steel and polypropylene fiber reinforced geopolymer. Construction and Building Materials, 161, 37-44. https://doi.org/10.1016/j.conbuildmat.2017.11.1 22

TS 706 EN 12620+A1. (2009). Aggregates for concrete. Turkish Standards Institution, Ankara-Turkey.

TS 802. (2016). Design of concrete mixes. Turkish Standards Institution, Ankara-Turkey.

TS EN 1008. (2003). Mixing water for concreteSpecifications for sampling, testing and assessing the suitability of water, including water recovered from processes in the concrete industry, as mixing water for concrete, Turkish Standards Institution, Ankara-Turkey.

TS EN 1097-6. (2013). Tests for mechanical and physical properties of aggregates - Part 6: Determination of particle density and water absorption. Turkish Standards Institution, Ankara-Turkey.

TS EN 1744-1:2009+A1. (2013). Tests for chemical properties of aggregates - Part 1: Chemical analysis. Turkish Standards Institution, AnkaraTurkey. 
Vaidya, S. and Allouche, E. N. (2011). Strain sensing of carbon fiber reinforced geopolymer concrete. Materials and structures, 44(8), 1467-1475. https://doi.org/10.1617/s11527-011-9711-3

Wang, Y., Zheng, T., Zheng, X., Liu, Y., Darkwa, J. and Zhou, G. (2020). Thermo-mechanical and moisture absorption properties of fly ash-based lightweight geopolymer concrete reinforced by polypropylene fibers. Construction and Building Materials, 251, 118960. https://doi.org/10.1016/j.conbuildmat.2020.1189 60

Worrell, E., Price, L., Martin, N., Hendriks, C. and Meida, L.O. (2001). Carbon dioxide emissions from the global cement industry. Annual Review of Energy and the Environment, 26(1), 303-329. https://doi.org/10.1146/annurev.energy.26.1.303

Yadollahi, M. M., Benli, A. and Demirboğa, R. (2015). The effects of silica modulus and aging on compressive strength of pumice-based geopolymer composites. Construction and Building Materials, 94, 767-774. https://doi.org/10.1016/j.conbuildmat.2015.07.0 52
Yunsheng, Z., Wei, S., Zongjin, L., Xiangming, Z. and Chungkong, C. (2008). Impact properties of geopolymer based extrudates incorporated with fly ash and PVA short fiber. Construction and Building Materials, 22(3), 370-383. https://doi.org/10.1016/j.conbuildmat.2006.08.0 06

Zhang, H., Wang, L., Zheng, K., Bakura, T. J. and Totakhil, P. G. (2018). Research on compressive impact dynamic behavior and constitutive model of polypropylene fiber reinforced concrete. Construction and Building Materials, 187, 584595.

https://doi.org/10.1016/j.conbuildmat.2018.07.1 64

Zivica, V. and Bajza, A. (2002). Acidic attack of cement-based materials-a review Part 2 . Factors of rate of acidic attack and protective measures. Construction and building materials, 16(4), 215-222. https://doi.org/10.1016/S09500618(02)00011-9

Zollo, R. F. (1997). Fiber-reinforced concrete: an overview after 30 years of development. Cement and concrete composites, 19(2), 107-122. https://doi.org/10.1016/S0958-9465(96)00046-7 